\title{
SUBJETIVIDADE ONTOLÓ. GICA NA FILOSOFIA DA MENTE DE JOHN SEARLE
}

Tárik de Athayde Prata (UFC) tarikbilden@vahoo.de

Resumo: Analisando uma conhecida crítica de John Searle à tradição materialista, segundo a qual essa tradição costuma ignorar ou mesmo recusar a subjetividade dos fenômenos mentais, o presente trabalho examina a estratégia de Searle para defender essa subjetividade, passando pela recusa do caráter essencial do comportamento para o mental (seção II), pela distinção entre subjetivo/objetivo no sentido epistêmico e ontológico (seção III) e pela solução de Searle para o problema de outras mentes (seção IV). Porém, a tentativa do filósofo de obter um acesso indireto aos fenômenos mentais subjetivos através de explanações causais (seção V) destes fenômenos por processos cerebrais se mostra insuficiente para integrar a subjetividade ontológica em nossa visão científica do mundo, na medida em que a suposta irredutibilidade ontológica dos fenômenos subjetivos a fenômenos objetivos parece levar ao resultado de que os fenômenos mentais sejam algo para além da realidade natural.

Palavras-chave: subjetividade, dualismo, problema mente-corpo.

\section{INTRODUÇÃO: OS FUNDAMENTOS DA TRADIÇÃO MATERIALISTA.}

Uma das principais críticas de John Searle à filosofia da mente dos últimos cinqüenta anos é que ela não trata adequadamente a subjetividade essencial dos fenômenos mentais. 
Mais do que isso, as vertentes dominantes da filosofia da mente, concebidas como formas de materialismo, teriam como motivação fundamental a negação dessa subjetividade. ${ }^{1}$ Searle indica dois motivos para esse estado de coisas. Primeiramente, a existência de fenômenos subjetivos parece incompatível com os resultados das ciências naturais, surgidas a partir da revolução científica do século XVII. ${ }^{2}$ Em segundo lugar, a filosofia produzida naquela época, em especial a partir da obra de Descartes, teria se fixado de tal modo na busca da fundamentação da ciência, que teria acabado por se concentrar excessivamente em questões epistêmicas, sempre em busca da objetividade do conhecimento. Desse modo, a filosofia dos séculos seguintes até os nossos dias, incluindo a tradição analítica, teria se habituado a perguntar "como se sabe acerca de algo?" em lugar de "o que é esse algo?”. E a colocação do primeiro tipo de pergunta no campo da filosofia da mente teria levado ao surgimento das diversas vertentes da tradição materialista:

Acredito que muito da esterilidade da filosofia da mente e da filosofia da linguagem deriva da suposição de que devemos começar com perguntas como 'Como sabemos que outra pessoa está em determinado estado mental? Como sabemos o que outra pessoa quer dizer através de uma declaração?' Essa é a suposição que baseia o behaviorismo, o funcionalismo, a tradução radical, a indeterminação do significado e todo o resto. (SEARLE 2001, p. 173)

Ao se colocar tais perguntas, referentes ao conhecimento dos fenômenos, espera-se alcançar respostas objetivas, independentes dos pontos de vista dos diversos investigadores, e essa busca por conhecimento objetivo teria levado à conclusão de que a própria realidade a ser conhecida tem de existir objetivamente: 
Desde que a ciência procura por objetividade no sentido epistêmico de que buscamos verdades que não são dependentes do ponto de vista particular desse ou daquele investigador, tem sido tentador concluir que a realidade investigada pela ciência deve ser objetiva no sentido de existir independentemente das experiências no humano individual. (SEARLE 2002a, p. 11)

Esse pressuposto ontológico fundamental, o de que a realidade é objetiva, surgido dessa tendência objetificante (cf. SEARLE 1997, p. 16 [28]) característica da filosofia e da ciência desde o século XVII, ${ }^{3}$ levaria à negação da subjetividade do mental, pois a realidade objetiva estudada pelas ciências não teria lugar para fenômenos que existem apenas na experiência de sujeitos particulares. E é justamente contra essa concepção do mental e da própria realidade que Searle se insurge ao defender a subjetividade. Segundo ele, é perfeitamente razoável aceitar os resultados da ciência moderna e, simultaneamente, reconhecer que os fenômenos mentais subjetivos existem, ${ }^{4}$ desde que se assuma a concepção que Searle considera a solução do problema mente-corpo, por ele chamada de Naturalismo Biológico: "Os processos e fatos mentais fazem parte de nossa história natural biológica tanto quanto a digestão, a mitose, a meiose ou a secreção enzimática." (SEARLE 1997, p. 1 [7]) Em sua reconstituição dos fundamentos da tradição materialista, ele identifica sete princípios que seriam essenciais para essa tradição ${ }^{5}$, dos quais apenas quatro são relevantes para os objetivos do presente trabalho:

2. A ciência é objetiva. (...) A ciência é objetiva porque a própria realidade é objetiva. (...) 3. Porque a realidade é objetiva, o melhor método para o estudo da mente é adotar o ponto de vista objetivo, ou da terceira pessoa. (...) 4. A partir do ponto de vista objetivo, de terceira pessoa, a única resposta à pergunta epistemológica 'Como conheceríamos os fenômenos mentais de outro sistema?' é: conhecemos pela observação de seu com- 
portamento. Esta é a única solução para o 'problema de outras mentes'. (...) 5. Comportamento inteligente e relações causais de comportamento inteligente são, em certo sentido, a essência do mental. (SEARLE 1997, p. 10-1 [25-6])

Primeiramente será apresentado o modo como Searle pretende refutar o quinto princípio. No terceiro capítulo de A Redescoberta da Mente ele recorre a alguns experimentos de pensamento para provar que a existência de fenômenos mentais é independente do comportamento (seção II). Mas ao afirmar que os fenômenos mentais são independentes do comportamento, ele sugere que tais fenômenos não são igualmente acessíveis a todos os observadores ${ }^{6}$, o que implica uma recusa do segundo princípio (o da objetividade da realidade). Para tornar a sua refutação dessa tese ontológica compreensível, Searle tenta, no segundo e no quarto capítulo de A Redescoberta da Mente, reformular a distinção entre subjetividade e objetividade, indicando que ambos os conceitos possuiriam tanto uma versão epistêmica quanto uma versão ontológica (seção III). Ele afirma então a existência de certos fenômenos, cuja existência seria um fato objetivo, embora tais fenômenos sejam subjetivos. Mas então se coloca o que eu chamaria de uma pergunta decisiva: como se relacionam a subjetividade e a objetividade? Searle tenta responder essa pergunta no que diz respeito ao problema de como se pode obter conhecimento (epistemicamente) objetivo sobre fenômenos mentais (ontologicamente) subjetivos. Como se pode afirmar que a existência de fenômenos subjetivos é um fato objetivo se tais fenômenos, por causa de sua subjetividade, não são acessíveis publicamente? Mesmo se Searle faz uma distinção entre uma versão epistêmica e uma versão ontológica dos conceitos de subjetividade e objetividade, ele tem de explicar como se pode estudar esses fenômenos ontologicamente subjetivos. Tal estudo passa pela resolução do problema 
das outras mentes (seção IV), o problema de como se pode saber que outros seres realmente instanciam propriedades mentais, se nós não temos um acesso direto a tais fenômenos. Ao tentar provar que a sua teoria pode evitar esse problema, Searle ataca o quarto princípio, rejeitando a idéia de que o comportamento é o único meio para se obter conhecimento acerca dos fenômenos mentais de outros seres. Ele afirma que nós podemos ter acesso aos fenômenos mentais de outros seres através de seu fundamento causal na neurobiologia (seção IV). Embora os fenômenos mentais de um sujeito permaneçam inacessíveis para os outros, pode-se obter um acesso indireto a eles, quando se investiga os processos neurobiológicos que estão na base desses fenômenos. Searle tenta integrar os fenômenos mentais no domínio dos fatos (ontologicamente) empíricos, ao indicar a possibilidade de se obter conhecimento objetivo dos fenômenos subjetivos através da investigação de fenômenos objetivos - ou seja, conhecimento objetivo da mente através do estudo do cérebro. A possibilidade de se obter conhecimento objetivo dos fenômenos mentais graças às suas conexões causais com processos cerebrais ${ }^{7}$ mostraria que a subjetividade (ontológica) do mental não representaria um problema insolúvel para nossa visão científica do mundo, pois a pesquisa científica do mental seria possível através de explanações causais do mental pelo neurobiológico (seção V). Mas eu penso que a pergunta decisiva (como se relacionam subjetividade e objetividade?) se coloca novamente em uma outra forma: como a investigação de fenômenos (ontologicamente) objetivos pode explicar os fenômenos (ontologicamente) subjetivos? Searle afirma que os fenômenos mentais podem ser explicados através de processos cerebrais. Mas a subjetividade do mental é considerada por muitos pensadores como um obstáculo colossal para uma tal explanação (seção VI). 


\section{A INDEPENDÊNCIA ENTRE FENÔMENOS MENTAIS E COMPORTAMENTO: CÉREBROS DE SILÍCIO E ROBÔS CONSCIENTES.}

Para iniciar a refutação do segundo princípio, Searle ataca o quinto princípio e procura mostrar que não existe uma conexão essencial entre o mental e o comportamento. Ele apresenta um experimento de pensamento para mostrar que a presença de fenômenos mentais sem comportamento, assim como de comportamento sem fenômenos mentais, é perfeitamente concebivel. Ele imagina um cenário em que, devido a uma doença degenerativa, os neurônios de uma pessoa fossem paulatinamente substituídos por chips de silício até que todo o seu cérebro fosse completamente reconstituído nesse material (cf. SEARLE 1997, p. 65-6 [98]). Em uma tal situação existiram, segundo Searle, três possibilidades. A primeira possibilidade é que os chips de silício pudessem produzir fenômenos mentais de um modo tal, que a vida mental e o comportamento da pessoa permanecessem inalterados. Sendo o mais famoso crítico do modelo computacional da mente, Searle considera naturalmente essa hipótese falsa, embora ele a reconheça como uma possibilidade conceitual. ${ }^{8}$ Uma segunda possibilidade é que os chips de silício pudessem dirigir o comportamento externo, mas não pudessem gerar fenômenos mentais. Nesse caso, a vida mental da pessoa iria desaparecer gradativamente, enquanto o comportamento exterior permaneceria inalterado (cf. SEARLE 1997, p. 66-7 [99-100]). Uma terceira possibilidade seria que os chips de silício pudessem produzir a vida mental, mas não fossem capazes de dirigir o comportamento externo. Em uma tal situação a pessoa não seria capaz de se expressar de nenhum modo, embora permanecesse completamente consciente. De fora pareceria que não há qualquer vida mental, em- 
bora ela permanecesse intacta (cf. SEARLE 1997, p. 67-8 [101]).

Com esse experimento de pensamento, Searle pretende tornar claras as relações causais que subsistiriam entre processos cerebrais, fenômenos mentais e comportamento externo. $\mathrm{Na}$ primeira variação Searle imagina que os chips de silício tivessem exatamente os mesmos poderes causais do cérebro, que produzem tanto os fenômenos mentais como o comportamento. $\mathrm{Na}$ segunda variação ele imagina que os chips pudessem produzir o comportamento, mas "não reproduziam as capacidades causais do cérebro de modo a produzir estados mentais conscientes" (SEARLE 1997, p. 68 [102]). E na terceira variação ele imagina que os chips de silício pudessem produzir a vida mental, mas não o comportamento. A partir da segunda e da terceira variações, ou seja, do fato de que é perfeitamente concebível que haja fenômenos mentais sem comportamento, assim como comportamento sem fenômenos mentais, Searle pensa poder concluir que fenômenos mentais e comportamento são, em um sentido importante, independentes. Do ponto de vista epistêmico, nós conhecemos os fenômenos mentais também através do comportamento, mas, do ponto de vista ontológico, o comportamento não tem nenhuma relação essencial com o mental. Este é o que Searle chama "princípio da independência de consciência e comportamento.” (SEARLE 1997, p. 69 [104]), ou seja, o comportamento seria completamente irrelevante para a existência dos fenômenos mentais:

Não há conexão lógica, não há conexão necessária entre estados mentais subjetivos, qualitativos, internos e comportamento externo publicamente observável. É claro que, factualmente, estados de consciência caracteristicamente causam um comportamento. Mas o comportamento que eles causam tem que ser distinguido dos estados em si. (SEARLE 2002a, p. 16) 
No que a segunda variação deixa claro que o comportamento pode estar presente sem uma vida mental subjacente a ele, ela mostra que o comportamento não é uma condição suficiente do mental. E no que a terceira variação deixa claro que fenômenos mentais podem existir sem o comportamento, ela mostra que o comportamento não é uma condição necessária para os fenômenos mentais. ${ }^{9}$ E se os fenômenos mentais são independentes do comportamento de um modo tão fundamental, então há um bom motivo para se afirmar que eles existem de um modo subjetivo. De acordo com Searle, esses experimentos de pensamento deixam claro que "a ontologia do mental é essencialmente uma ontologia de primeira pessoa. Essa é apenas uma maneira imaginosa de dizer que todo estado mental tem que ser um estado mental de alguém. Os estados mentais só existem como fenômenos subjetivos, de primeira pessoa.” (SEARLE 1997, p. 70 [104]). A argumentação para a tese da subjetividade ontológica dos fenômenos mentais pode ser considerada por muitos como inaceitável, mas Searle procura abalar a confiança na tese (oposta) da objetividade (ontológica) da realidade ao articular a distinção entre subjetivo e objetivo de um modo próprio.

\section{NEM TODA A REALIDADE É OBJETIVA: A DISTIN- ÇÃO ENTRE SUBJETIVIDADE EPISTÊMICA E ONTO- LÓGICA.}

Ao recusar a tese objetivista de que todo o real tem de ser objetivo, Searle afirma que a tradição materialista confunde os sentidos ontológico e epistêmico dos termos "objetivo" e "subjetivo”. Searle afirma então que há uma subjetividade ontológica, ou seja, que alguns fenômenos têm um modo de existência subjetivo. Contra a concepção de que todo fato tem de existir de 
modo objetivo (independente de sujeitos), ele afirma: "Nem toda a realidade é objetiva; parte dela é subjetiva." (SEARLE 1997, p. 19 [32]) Searle explica os dois diferentes sentidos da distinção entre subjetivo e objetivo da seguinte maneira:

Epistemicamente, a distinção discrimina diferentes graus de independência de asserções em relação aos caprichos de valores especiais, preconceitos pessoais, pontos de vista e emoções. Ontologicamente, a distinção determina categorias diferentes de realidade empírica. (SEARLE 1997, p. 19 [32])

No sentido epistêmico trata-se da questão sobre em que medida se pode constatar, independentemente de tendências pessoais, que um juizo é verdadeiro ou falso. Sobre o sentido epistêmico da distinção Searle escreve:

Muitas vezes falamos de juízos 'subjetivos' quando queremos dizer que sua verdade ou falsidade não pode ser estabelecida 'objetivamente', porque verdade ou falsidade não é uma simples questão de fato, mas depende de determinadas atitudes, sentimentos e pontos de vista dos autores e ouvintes do juízo. Um exemplo de tal juízo podia ser: 'Van Gogh é um artista melhor do que Matisse.' Neste sentido de subjetividade, contrastamos tais juízos subjetivos com juízos completamente objetivos, como este: 'Matisse viveu em Nice durante o ano de 1917.' Para tais juízos objetivos, podemos verificar que espécie de fatos no mundo os tornam verdadeiros ou falsos, independentemente das atitudes e sentimentos de qualquer pessoa em relação a eles. (SEARLE 1997, p. 94 [139])

A tradição materialista procura por objetividade, e por isso a subjetividade característica dos fenômenos mentais parece algo indesejado. Porém esse seria um grande erro. ${ }^{10}$ A questão dos fenômenos mentais subjetivos seria também uma questão de fatos, uma questão que poderia ser respondida independentemente de inclinações e preferências subjetivas, embora tais 
fenômenos pertençam ao conteúdo de uma consciência, que seria acessível apenas para o seu portador (o sujeito consciente) e de um certo modo dependam dele para existir. Searle dá o seguinte exemplo para a subjetividade ontológica:

Considere, por exemplo, a afirmação: 'Agora tenho uma dor na parte inferior das minhas costas.' Essa afirmação é completamente objetiva no sentido de que é tornada verdadeira pela existência de um fato real, e não é dependente de nenhuma posição, atitude ou opinião de observadores. Entretanto, o próprio fenômeno, a própria dor real, tem um modo subjetivo de existência, e é neste sentido que eu estou dizendo que a consciência é subjetiva. [grifo meu] (SEARLE 1997, p. 94 [139-40])

Enquanto no âmbito epistêmico trata-se de juizos, tanto objetivos quanto subjetivos, trata-se no âmbito ontológico de entidades $^{11}$, entidades abertas por um lado, que são publicamente acessíveis, e entidades privadas por outro lado, que são acessíveis apenas para um sujeito. $\mathrm{O}$ modo como Searle concebe a subjetividade ontológica, o modo de existência dessas entidades privadas, é apresentado em uma passagem bastante esclarecedora:

Apesar de a consciência ser um fenômeno biológico, ela tem algumas características que outros fenômenos biológicos não têm. O mais importante deles é o que tenho chamado de sua 'subjetividade'. Há um sentido no qual a consciência de cada pessoa é privada para ela, um sentido no qual ele é relacionado a suas dores, cócegas, coceiras, pensamentos e sentimentos de uma forma que é bem diferente da maneira que outros se relacionam a suas dores, cócegas, coceiras, pensamentos e sentimentos. Esse fenômeno pode ser descrito de várias maneiras. Ele é às vezes descrito como uma característica da consciência, pela qual existe algo que é como estar ou como se sente [it feels like] estar em um certo estado consciente. (SEARLE 2002a, p. 7-8) 
Devido ao fato de serem essencialmente caracterizados por um aspecto qualitativo, os fenômenos mentais existiriam apenas enquanto são experienciados por um sujeito ${ }^{12}$, de modo que seriam acessíveis somente a ele. É muito importante notar que esse modo de existência subjetivo formaria um domínio irredutivel ao domínio dos fenômenos (ontologicamente) objetivos. Segundo Searle, a história do materialismo mostra que toda tentativa de identificar os fenômenos subjetivos com algum fenômeno objetivo acaba por deixar a mente de fora (cf. SEARLE 1997, p. 30 [47-8]), simplesmente porque a mente é algo que existe de modo diferente dos fenômenos objetivos. ${ }^{13}$ E essa diferença ontológica entre subjetividade e objetividade seria evidenciada pelo fato de os dois tipos de fenômenos exigirem um vocabulário próprio a eles para sua descrição. Segundo Searle os fenômenos ontologicamente subjetivos não podem ser descritos em termos objetivos:

O ponto principal de ter o conceito de consciência é capturar a primeira pessoa, as características subjetivas do fenômeno, e esse ponto está perdido se redefinirmos a consciência em terceira pessoa, em termos objetivos. Nós ainda precisaríamos de um nome para a ontologia da consciência em primeira pessoa. (...) Você poderia fazer uma redução da consciência e intencionalidade, mas você ainda precisaria de um vocabulário para falar das características superficiais. [grifos meus] (SEARLE 2004, p. 120)

Essa suposta impossibilidade de se descrever os fenômenos mentais em termos de fenômenos objetivos (p. ex. comportamentais ou neurobiológicos) será de grande importância quando se for avaliar a sustentabilidade da concepção de Searle acerca da subjetividade (cf. seção VI). Em suma, Searle pensa que a asserção "Eu sinto agora uma dor na parte baixa das minhas costas” é objetiva, pois é tornada verdadeira (pressupondo-se que ela é verdadeira) por um fato, a saber, o fato de 
que uma dor é sentida por mim, e isso de um modo totalmente independente de preferências pessoais e de pré-concepções. Porém, no que diz respeito à dor mesma, não se trata de um fato que existisse independentemente de qualquer sujeito e que fosse acessível para qualquer observador. No meu modo de entender, o ponto aonde Searle quer chegar é o seguinte: tanto entidades objetivas quanto entidades subjetivas podem ser objeto de juizos objetivos. Exatamente como o juízo 'Matisse viveu em Nice em 1917' é objetivo, também o juízo 'Eu sinto agora uma dor nas costas' seria epistemicamente objetivo, pois esse segundo juízo é tornado verdadeiro por um fato (embora esse fato seja subjetivo).

Mas como é possível que um fenômeno subjetivo possa ser tema de juízos objetivos? ${ }^{14}$ Como é que nós podemos conhecer os fenômenos subjetivos se eles são totalmente privados? E quando se pretende investigar os fenômenos mentais cientificamente essa subjetividade ontológica parece ser ainda mais estranha. Como pode haver uma investigação científica da mente se não se pode ter evidências publicamente acessíveis dos fenômenos mentais?

\section{O PROBLEMA DAS OUTRAS MENTES E A SOLU. ÇÃO DE SEARLE: A NATUREZA BIOLÓGICA DO MENTAL}

Em uma resenha do livro Mente, Cérebro e Ciência, Stich afirma que Searle, por aceitar o caráter subjetivo dos fenômenos mentais, seria um dualista de propriedades. Stich menciona as quatro características que, segundo Searle, toda teoria satisfatória sobre a mente deve explicar ${ }^{15}$, destacando a subjetividade. Searle diz que os fenômenos mentais são dependentes das especificidades biológicas do nosso cérebro e que progra- 
mas de computador não são suficientes para produzir tais fenômenos. Mas se os fenômenos mentais são de tal modo subjetivos que eles só são acessíveis para o seu portador, como é que nós podemos saber que programas de computador não são suficientes para produzir nossa vida mental? Stich escreve:

O problema com tudo isso é que se Searle está certo sobre a natureza subjetiva dos estados mentais, então é difícil de ver como poderíamos saber se os marcianos realmente tiveram vidas mentais. Como poderíamos saber que a gosma verde estava duplicando os processos mentais subjetivos, mais do que simulando-os? É igualmente difícil de ver como Searle poderia saber que instanciar o programa de computador certo não é suficiente para mentalidade real, subjetiva. (STICH 1987, p. 131)

Por esse motivo Stich conclui que Searle permanece preso às "velhas e esgotadas categorias" da filosofia da mente, apesar de sua suposta recusa a tais categorias. Por isso ele seria um dualista de propriedades, incapaz de lidar com o problema de outras mentes:

Como qualquer dualista, ele é assolado pelo problema de outras mentes - o problema de como eu poderia saber que qualquer pessoa ou qualquer coisa no universo tem estados mentais. Mas, diferente da maioria dos outros dualistas, Searle se recusa a entender ou sequer admitir a existência do problema. Ele parece pensar que se ele menciona cérebros e biologia o suficiente, de algum modo o problema irá simplesmente desaparecer. (STICH 1987, p. 133)

Penso que Searle tem em vista exatamente essa resenha de Stich quando formula sua solução do problema de outras mentes. ${ }^{16}$ Ao apresentar a sua solução para esse problema, ele afirma que normalmente se faz uma confusão entre os sentidos ontológico e epistêmico do termo "empírico" 17 , e sua tentativa é mostrar que existem fatos ontologicamente empíricos que não se- 
riam comprováveis através de meios empíricos epistêmicos. Para provar isso ele recorre a um exemplo inspirado no influente texto de Thomas Nagels, What is it like to be a bat? (1974): segundo pesquisas recentes, alguns pássaros navegam com a ajuda de uma percepção do campo magnético da terra. Se é assim, chega-se a um interessante resultado. Se os pássaros, que navegam através da sua percepção do campo magnético, possuem uma experiência consciente do magnetismo, é uma questão de fatos empíricos, porém isso não é acessível para nós, seres humanos. Nenhum ser humano é capaz de imaginar essa experiência. Isso significa que o exato caráter qualitativo desse fato empírico não pode ser investigado através dos métodos padrão da pesquisa empírica.

Searle afirma que a existência de uma sensação de magnetismo é uma questão de fato empírico, o que indica que os fatos empíricos em sentido ontológico abrangem tanto a objetividade quanto a subjetividade ontológicas, ainda que os fatos ontologicamente subjetivos não sejam comprováveis através de meios empíricos (de modo que eles não seriam "fatos empíricos" em sentido epistêmico). No entanto, ele não acredita que a aceitação da subjetividade ontológica e das limitações dos métodos empíricos comuns nos obrigue a romper com a nossa visão científica do mundo, pois os fatos ontologicamente subjetivos poderiam ser pesquisados cientificamente através de sua natureza biológica. O princípio que poderia resolver o problema de outras mentes não seria "mesmo-comportamento-portantomesmos-fenômenos-mentais" mas sim "mesmas-causas-mesmosefeitos e causas-relevantemente-similares-efeitos-relevantemente-similares" (SEARLE 1997, p. 22 [36]). ${ }^{18}$ O comportamento pode, de acordo com Searle, ser concebido como manifestação de uma vida mental subjacente porque se poderia constatar o fundamento causal do mental na neurofisiologia: 
Naquilo que diz respeito ao conhecimento de outras mentes, o comportamento sozinho não tem interesse para nós; é antes a combinação do comportamento com o conhecimento dos sustentáculos causais do comportamento que forma a base de nosso conhecimento. (SEARLE 1997, p. 22 [36])

Sobre o tema da atribuição de estados mentais a animais, Searle declara estar completamente convencido de que animais superiores possuem estados mentais conscientes, e ele fundamenta essa convicção não apenas no comportamento, mas também na base causal do comportamento na fisiologia:

Ora, por que estou tão convencido disso? (...) Não é meramente porque o cachorro se comporta de uma maneira que é peculiar à existência de estados mentais conscientes, mas também porque posso ver que o fundamento causal do comportamento na fisiologia do cachorro é relevantemente parecido com o meu próprio. [grifo meu] Não é apenas que o cachorro tenha uma estrutura como a minha, e que tenha um comportamento interpretável de formas análogas à maneira como interpreto o meu próprio. Mas, mais exatamente, é na combinação desses dois fatos [grifo meu] que posso perceber que o comportamento é apropriado, e que tem a causação apropriada na fisiologia subjacente. (SEARLE 1997, p. $73[109-10])$

Somente a combinação do comportamento com o fundamento causal biológico pode justificar a atribuição de fenômenos mentais a outros seres vivos. Essa referência ao fundamento biológico dos fenômenos mentais evidencia o importante papel da explanabilidade causal do mental através do neurobiológico na teoria de Searle.

\section{O PAPEL DA EXPLANABILIDADE CAUSAL DA MENTE NA CRÍTICA DO OBJETIVISMO}


Para Searle, a pesquisa científica dos fenômenos mentais subjetivos seria possibilitada pela explanação causal desses fenômenos através dos processos cerebrais (caso uma tal explanação já estivesse à nossa disposição). Naturalmente, ele reconhece que ainda estamos muito afastados de um tal conhecimento, tanto no caso dos seres humanos quanto no dos animais superiores, mas é extremamente otimista e pensa que tal conhecimento poderia ser fornecido por uma teoria causal (cf. SEARLE 2004, p. 146). Ao apresentar o modo como se poderia alcançar um acesso indireto aos fenômenos mentais de outros seres, Searle aponta para a possibilidade de uma teoria que pudesse encontrar as causas neurofisiológicas da consciência:

Suponha que tivéssemos uma descrição do fundamento neurofisiológico da consciência nos seres humanos. Suponha que tivéssemos causas bastante precisas, neurofisiologicamente isoláveis, de consciência em seres humanos, tais que a presença dos fenômenos neurofisiológicos relevantes fosse tanto necessária quanto suficiente para a consciência. Se você tivesse isto, seria consciente; se você o perdesse, tornar-se-ia inconsciente. [grifos meus] (SEARLE 1997 , p. $74[111])^{19}$

Tal teoria colocaria uma explanação causal da consciência à nossa disposição, ou seja, poderia nos dizer exatamente quais processos cerebrais causam a consciência. Designemos esses supostos processos cerebrais como "x". Searle propõe um teste para o caráter causal da relação entre processos cerebrais e consciência:

Suponha, ainda, que a remoção de $\mathrm{x}$ da neurofisiologia de qualquer ser humano imediatamente produzisse inconsciência, e que sua reintrodução produzisse consciência. Em tal caso, parece-me que poderíamos admitir plausivelmente que a presença 
de $\mathrm{x}$ desempenhasse um papel causal crucial na produção da consciência. (SEARLE 1997, p. 74-5 [111])

Se estivéssemos justificados em supor que os processos cerebrais x causam os nossos estados de consciência, poderíamos concluir que a consciência é uma parte da natureza acessível à nossa investigação científica. Esse é o papel da explanabilidade causal na crítica ao objetivismo: depois de ter reconhecido a subjetividade ontológica, Searle tenta provar que essa subjetividade não é um problema insuperável para a nossa visão científica do mundo. A possibilidade de se construir uma teoria causal do mental através do neurobiológico tornaria compreensível como os fenômenos ontologicamente subjetivos podem ser pesquisados através de métodos científicos. Agora eu me volto para a tarefa de esclarecer as relações entre esses diferentes tipos de objetividade e subjetividade distinguidos por Searle.

\section{A PERGUNTA DECISIVA: COMO SE RELACIONAM SUBJETIVIDADE E OBJETIVIDADE?}

Searle quer mostrar que o modo de existência subjetivo dos fenômenos mentais é aceitável, incluindo esses fenômenos no âmbito dos fatos (ontologicamente) empíricos. Embora os fenômenos mentais não sejam igualmente acessíveis a todos, seriam, apesar disso, reais. E na medida em que seriam fenômenos reais, poderíamos ter a esperança de encontrar meios empíricos para pesquisá-los. Todo o domínio dos fatos empíricos, tanto os fatos (ontologicamente) objetivos quanto os (ontologicamente) subjetivos, seria tema de juízos objetivos, de modo que uma objetividade (epistêmica) em relação aos fenômenos mentais seria possível: "podemos ter conhecimento e- 
pistemicamente objetivo de domínios que são ontologicamente subjetivos." (SEARLE 2002a: 23)

Porém, a mera distinção entre subjetividade epistêmica (a dependência em relação a opiniões e preferências) e subjetividade ontológica (um modo de existência subjetivo) não é suficiente para estabelecer a existência de uma subjetividade ontológica, pois enquanto não se tiver acesso aos fenômenos ontologicamente subjetivos, os seguidores da tradição materialista irão recusar os fenômenos mentais (tradicionalmente concebidos) enquanto objeto da ciência. Searle tem a obrigação de esclarecer como se pode obter um acesso aos fenômenos mentais subjetivos de modo a se atingir um conhecimento objetivo acerca deles. Trata-se da pergunta decisiva acerca da relação entre objetividade e subjetividade, mas especificamente acerca da objetividade epistêmica e subjetividade ontológica.

Figura 1:

(acerca dos)

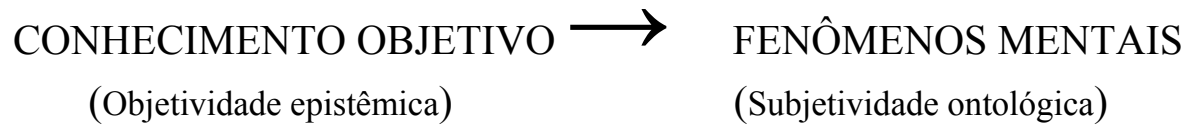

A resposta de Searle é que se pode obter um acesso indireto $^{20}$ aos fenômenos mentais, quando se investigam os processos cerebrais que subjazem a eles. Um conhecimento objetivo acerca do mental seria possível graças às relações causais entre processos cerebrais e fenômenos mentais (relações que, supostamente, tornam esses fenômenos causalmente explicáveis através daqueles processos), e na medida em que um conhecimento objetivo sobre esses fenômenos seria possível, eles estariam integrados no domínio dos fatos (ontologicamente) empíricos e com isso integrados na nossa visão científica do mundo. ${ }^{21} \mathrm{~A}$ relação entre objetividade epistêmica e subjetividade ontológi- 
ca seria possível através da mediação da objetividade ontológica. É de importância crucial atentar para o seguinte fato: a relação entre objetividade epistêmica e subjetividade ontológica (ou seja, a possibilidade de um conhecimento objetivo acerca dos fenômenos mentais) seria viabilizada pela suposta explanabilidade causal do mental (subjetividade ontológica) pelo neurobiológico (objetividade ontológica). Através da mediação dos processos cerebrais poderíamos obter um conhecimento objetivo acerca dos fenômenos mentais.

Figura 2:

$$
\text { (acerca dos) (explicam os) }
$$

CONHECIMENTO

OBJETIVO

$\rightarrow$ PROCESSOS CEREBRAIS $\rightarrow$ FENÔMENOS MEN-

TAIS

(Objetividade epistêmica)

ca)

(Objetividade ontológica)

(Subjetividade ontológi-

Neste ponto eu gostaria de apontar para uma certa limitação da argumentação de Searle. Ele diz que a tradição materialista recusaria a subjetividade dos fenômenos mentais porque essa tradição estaria sendo guiada por questões epistêmicas e estaria confundindo a subjetividade ontológica (o modo de ser dos fenômenos mentais) com a subjetividade epistêmica (a relatividade de juízos a preferências e atitudes). ${ }^{22}$ Receio que essas reflexões acerca de tal confusão não são tão úteis quanto Searle parece pensar, pois essa suposta confusão não é o único motivo para se recusar a subjetividade ontológica. Mesmo se dispuséssemos de meios indiretos para ter acesso aos fenômenos ontologicamente subjetivos $^{23}$ ainda haveria motivos para se considerar a subjetividade ontológica como problemática. Mesmo que não se confunda a subjetividade ontológica com a epistêmica, existe ainda um problema acerca da relação entre 
objetividade ontológica (processos cerebrais) e subjetividade ontológica (fenômenos mentais), uma relação de importância essencial para a solução de Searle para o problema de outras mentes. De acordo com ele, as características subjetivas dos estados de consciência não podem ser expressas através da descrição de fatos objetivos (como, p.ex., neurobiológicos), uma vez que os fenômenos subjetivos seriam fundamentalmente diferentes dos fenômenos objetivos. Argumentando para a tese da irredutibilidade ontológica da consciência a fenômenos objetivos, ele escreve: "Nenhuma descrição dos fatos de terceira pessoa, objetivos, fisiológicos comunicaria [convey] o caráter subjetivo, de primeira pessoa, da dor, simplesmente porque as características de primeira pessoa são diferentes das características de terceira pessoa." (SEARLE 1997, p. 117 [170]) A impossibilidade de se expressar os fenômenos ontologicamente subjetivos através da descrição de fenômenos ontologicamente objetivos seria devida ao fato de eles serem, do ponto de vista do modo de existência, essencialmente diferentes. ${ }^{24}$ Mas o ponto crucial é que essa impossibilidade de expressão (decorrente da irredutibilidade) parece inviabilizar uma explanação do mental através do neurobiológico, pois se uma descrição dos fatos neurobiológicos não é sequer capaz de exprimir o caráter subjetivo dos fenômenos mentais, então parece impossível que esses fatos possam explicar tal caráter subjetivo, ou seja, parece impossível que o recurso a fatos neurobiológicos possa mostrar o porquê de o caráter subjetivo dos fenômenos mentais ser tal como ele é. ${ }^{25}$ Para responder a essa objeção, Searle provavelmente diria que concebe a explanação de uma outra maneira, que a explanação de um fenômeno não exige que este seja mostrado como epistemicamente necessário a partir dos fatos que o explicam. Tal concepção de explanação foi proposta por Joseph Levine, que escreveu em um influente texto: 
A idéia básica é que a redução deve explicar o que é reduzido, e a forma que dizemos se isso tem sido atingido é ver se o fenômeno a ser reduzido é epistemologicamente necessitado pela redução do fenômeno, ou seja, se podemos ver por que, dados os fatos citados na redução, as coisas devem ser da maneira que parecem na superfície. (LEVINE 1997, p. 548)

Creio que Searle entende sua própria concepção de explanação como sendo mais modesta do que essa. Ele afirma que os fenômenos mentais são causalmente explicáveis pelos processos cerebrais. Para resolver o problema de outras mentes (e outras dificuldades relativas ao problema mente-corpo) Searle defende (ao mesmo tempo em que recusa a redução ontológica) uma forma de reducionismo causal ${ }^{26}$ que possibilitaria a explanação dos estados de consciência pelos processos do cérebro. Cumpre notar que essa explanação causal consistiria simplesmente na constatação de leis causais conectando o fenômeno que explica (explanans) ao fenômeno que é explicado (explanandum). A esse respeito ele escreve: "O conhecimento das relações causais lawlike nos fornecerá toda a necessidade causal de que precisamos." (SEARLE 1997, p. 103 [152]) Mas é bastante discutível se uma tal concepção de explanação é realmente satisfatória ${ }^{27}$, pois não é claro se essa concepção é capaz de assegurar o caráter biológico dos fenômenos mentais.

Se, pelo fato de existirem de um modo essencialmente diferente, os fenômenos mentais não podem ser expressos pela descrição dos processos cerebrais, então os conceitos biológicos pelos quais estes processos são descritos são completamente inadequados para exprimir os fenômenos mentais. Mas se estes fenômenos não podem ser expressos através de conceitos biológicos, que razão temos nós para considerá-los como fenômenos biológicos? A suposta relação causal entre fenômenos tão radicalmente distintos não seria suficiente para que ambos 
pudessem ser considerados como pertencentes ao mesmo tipo, afinal uma das concepções historicamente mais influentes acerca do mental, o dualismo interacionista de Descartes, consistia justamente na idéia de que a mente seria uma entidade de tipo essencialmente diferente das entidades físicas (na realidade uma entidade não-fisica) mas ainda assim capaz de interagir causalmente com estas. O modo como Searle concebe a subjetividade ontológica parece acabar tornando a sua teoria (apesar de todo o esforço dele em recusar essa conclusão - cf. 2002b) uma forma de dualismo. Apesar de seu esforço em apresentar o seu Naturalismo Biológico como uma superação tanto do dualismo quanto do materialismo tradicionais - cf. Searle (2000) - a forma como ele contrasta o modo de existência subjetivo com o objetivo parece ser dualista. ${ }^{28} \mathrm{~A}$ diferença ontológica (entre subjetivo e objetivo) afirmada pelo filósofo parece levar a uma concepção do mental que não é compatível com o suposto caráter biológico dos fenômenos mentais. Searle escreve:

Nós deveríamos pensar na consciência como parte da nossa história biológica comum, paralelamente com a digestão, crescimento, mitose e meiose. No entanto, apesar da consciência ser um fenômeno biológico, ela tem algumas características que outros fenômenos biológicos não têm. $\mathrm{O}$ mais importante deles é o que tenho chamado de sua 'subjetividade'. Há um sentido no qual a consciência de cada pessoa é privada para ela, (...) (SEARLE 2002a, p. 7)

Mas se a consciência, o fenômeno mental central ${ }^{29}$, possui características que nenhum outro fenômeno biológico possui, sendo tais características de tal magnitude que levam a uma diferença ontológica, então temos fortes motivos para duvidar de que os fenômenos mentais sejam realmente biológicos. $\mathrm{Na}$ verdade, poder-se-ia ir ainda mais longe e afirmar que a distin- 
ção entre modos de existência torna questionável até mesmo o caráter pretensamente natural dos fenômenos mentais, na medida em que, evidentemente, a subjetividade ontológica como entendida por Searle não é encontrada em nenhum outro fenômeno natural. ${ }^{30}$

\section{CONSIDERAÇÕES FINAIS.}

Searle critica a tradição materialista pelo fato de que ela tenta recusar a subjetividade dos fenômenos mentais. Segundo ele, a recusa nasce do fato de essa tradição assumir uma atitude epistêmica e, a partir dessa atitude, articular a temática ontológica. A busca por conhecimento objetivo acabaria levando à idéia de que tudo tem de existir objetivamente. Contra essa idéia Searle afirma que certos fenômenos existem de um modo subjetivo (ontologia), o que não nos impede de obter conhecimento objetivo acerca deles (epistemologia), já que os fenômenos mentais (ontologicamente subjetivos) seriam causalmente explicáveis pelos processos cerebrais (ontologicamente objetivos). Minha crítica a Searle é que a distinção entre os sentidos epistêmico e ontológico da subjetividade e a pretensa possibilidade de obtenção de conhecimento objetivo acerca do ontologicamente subjetivo não são suficientes para dissipar os problemas em torno da subjetividade ontológica. Essa concepção de um modo de existência subjetivo, por si mesma, levanta sérias dificuldades, que parecem colocar em questão a posição filosófica mais fundamental de Searle: o seu naturalismo. As reflexões de Searle acima expostas acabam por se mostrar insuficientes para tornar a subjetividade ontológica aceitável, pois fenômenos que existiriam de modo irredutivelmente subjetivo parecem extremamente difíceis de se integrar no domínio dos fenômenos físicos (em geral) ou mesmo biológicos (em particu- 
lar), ou seja, parecem resistir duramente à idéia de que eles seriam fenômenos naturais de algum tipo. ${ }^{31}$

\begin{abstract}
This paper contains an analysis of a famous criticism from John Searle on materialist tradition. This tradition uses to ignore or even refuse the subjectivity of mental phenomena. This paper examines Searle's strategy to defend this subjectivity, refusing the essential character of behavior to the mental aspect (section II), distinguishing subjective and objective in epistemic and ontological senses (section III) and showing his solution to the problem of other minds (section IV). However, his attempt to obtain an indirect access to subjective mental phenomena through causal explanations (section V) of these phenomena by brain processes is not enough to integrate the ontological subjectivity in our scientific worldview, once that this supposed ontological irreducibility from subjective to objective phenomena seems to result in the conclusion that mental phenomena are something beyond natural reality.
\end{abstract}

Keywords: subjectivity, dualism, mind-body problem.

\title{
NOTAS
}

1 "Se tivéssemos de descrever a mais profunda motivação do materialismo, poderíamos dizer que é simplesmente um horror à consciência. Mas deveria ser assim? Por que deveriam os materialistas temer a consciência? (...) A razão mais profunda para o medo da consciência é que a consciência tem a característica apavorante da subjetividade." (SEARLE 1997, p. 55 [82-3]). O primeiro número indica a página da edição original, enquanto o número entre colchetes (quando houver) indica a página da edição brasileira ou portuguesa. Quando um artigo ou livro estrangeiro for citado sem número entre colchetes, isso significa que o texto em inglês foi traduzido por mim. Agradeço a Ananda Badaró pela revisão das traduções. 
2 "Muitos pensam que, dadas as descobertas das ciências físicas, uma concepção da realidade que negue a existência da subjetividade é a única que se possa ter." (SEARLE 1997, p. 55 [83])

3 Ao reconstituir as origens históricas da tradição materialista (cf. SEARLE 1997, p. 12-8 [22-30]), Searle menciona, além dessa tendência objetificante, o terror ao dualismo, o vocabulário do dualismo conceitual e a busca por uma descoberta teórica contra-intuitiva. Os objetivos do presente trabalho, entretanto, dizem respeito apenas a essa obsessão pela objetividade.

4 "Podemos aceitar os fatos óbvios da física - que o mundo consiste inteiramente de partículas físicas dentro de campos de força - sem negar que entre as características físicas do mundo há fenômenos biológicos como estados internos qualitativos de consciência e intencionalidade intrínseca." (SEARLE 1997, p. xii [2-3])

5 É muito interessante considerar a seguinte declaração de Daniel Dennett: "Acredito que ele está quase exatamente certo sobre essa lista de fundamentos. Como um alvo representativo da ortodoxia, eu particularmente aceito todas as sete proposições... Eu diria que Searle tem feito um bom trabalho em identificar o inimigo e suas suposições fundamentais." (DENNETT 1993, p. 194)

6 Searle caracteriza a consciência (característica essencial para a existência efetiva de fenômenos mentais) através de seu caráter privado: "a consciência é por sua própria natureza subjetiva e, em algum sentido pelo menos, 'privada' e 'interna', não igualmente acessível a todos os observadores competentes." (SEARLE 1994, p. 545)

7 A tese de Searle segundo a qual a relação entre processos cerebrais (no nível microscópico) e fenômenos mentais (no nível macroscópico) é de natureza causal é freqüen- 
temente discutida e criticada na literatura secundária (cf., p. ex., THOMPSON 1986, p. 95; KIM 1995, p. 194; CHURCHLAND 1994, p.14 ). A análise desse interessante debate encontra-se infelizmente para além dos objetivos do presente trabalho.

8 "Apresso-me em acrescentar que não penso de modo algum que tal fato seja nem sequer remotamente possível na prática. Considero empiricamente absurdo supor que pudéssemos reproduzir inteiramente as capacidades causais de neurônios em silício. Mas esta é uma asserção empírica de minha parte. Não se trata de algo que pudéssemos estabelecer a priori. Assim, o experimento de pensamento permanece válido como um enunciado de possibilidade lógica ou conceitual.” (SEARLE 1997, p. 66 [99])

9 Searle também apresenta no terceiro capítulo de A Redescoberta da Mente o experimento de pensamento dos robôs conscientes (cf. SEARLE 1997, p. 70-1 [105-6]), para apoiar a mesma conclusão.

10 "Epistemicamente, o ideal de objetividade expressa uma meta que vale a pena, mesmo se inalcançável. Em termos ontológicos, porém, a asserção de que toda a realidade é objetiva é, neurobiologicamente falando, simplesmente falsa. Em geral, os estados mentais têm uma ontologia irredutivelmente subjetiva, (...)” (SEARLE 1997, p. 19 [32])

11 Em The Construction of Social Reality Searle escreve: "Epistemologicamente falando, 'objetivo' e 'subjetivo' são primariamente predicados de juízos. Nós freqüentemente falamos de juízos como sendo 'subjetivos' quando queremos dizer que sua verdade ou falsidade não podem ser resolvidos 'objetivamente', porque a verdade ou falsidade não é um simples fato mas depende de certas atitudes, sentimentos e pontos de vista dos que criam e dos que 
ouvem o juízo.(...) No sentido ontológico, 'objetivo' e 'subjetivo' são predicados de entidades e tipos de entidades, e eles atribuem modos de existência." (SEARLE 1995, p. 8 , grifos meus)

12 "Estados de consciência existem somente quando são experimentados por algum sujeito humano ou animal. Nesse sentido, eles são essencialmente subjetivos. Eu costumava tratar a subjetividade e a qualitatividade como características distintas, mas agora me parece que propriamente entendido, qualitatividade implica em subjetividade, porque com o fim de haver um sentimento qualitativo por algum evento, deve haver algum sujeito que experimenta o evento." (SEARLE 2002a, p. 40)

13 Ao recusar a possibilidade de uma redução ontológica (que seria uma afirmação de identidade - cf. Searle (1997, p. 112-3) do mental aos processos cerebrais, Searle afirma que "as características de primeira pessoa são diferentes das características de terceira pessoa." (SEARLE 1997, p. 117, grifo meu)

14 Aqui se trata da pergunta decisiva sobre a relação de subjetividade e objetividade, mas em relação especificamente à objetividade epistêmica e à subjetividade ontológica.

15 Consciência, Intencionalidade, Subjetividade e Causação Mental. (cf. SEARLE 1987, p. 17 [22])

16 A resenha de Stich é citada em A Redescoberta da Mente e o modo como Searle trata esse problema no terceiro capítulo do livro sugere um conhecimento exato do texto de Stich.

17 "Quando as pessoas falam de fatos empíricos, algumas vezes querem dizer fatos reais, contingentes do mundo, em oposição a, digamos, fatos da matemática ou da lógica. Mas por vezes, quando as pessoas falam de fatos empíricos, querem dizer fatos que sejam verificáveis por méto- 
dos de terceira pessoa, isto é, por 'fatos empíricos' e 'métodos empíricos' querem dizer fatos e métodos que sejam acessíveis a todos os observadores competentes. Então essa ambigüidade sistemática no emprego da palavra 'empírico' sugere algo que é certamente falso: que todos os fatos empíricos, no sentido ontológico de serem fatos do mundo, são igualmente acessíveis epistemicamente a todos os observadores competentes. Sabemos, de modo independente, que isto é falso." (SEARLE 1997, p. 72 [107-8])

18 Sobre o procedimento behaviorista, Searle escreve ironicamente: "Se esse princípio estivesse correto, todos teríamos que concluir que os rádios são conscientes porque exibem comportamento verbal inteligente. Mas não tiramos qualquer conclusão desse tipo, porque temos uma 'teoria' sobre como os rádios funcionam." (SEARLE 1997, p. 22 [36]) cf. (SEARLE 1994, p. 545).

19 Cf. (SEARLE 2002a, p. 50): "Para estabelecer necessidade, descobrimos se um sujeito que tem o suposto NCC removido logo perde a consciência, para estabelecer a suficiência, nós descobrimos se algum sujeito inconsciente de outro modo pode ser trazido à consciência induzido pelo suposto NCC."

20 "Embora em alguns casos não tenhamos acesso apropriado a determinados fatos empíricos por causa de sua subjetividade intrínseca, em geral, temos métodos indiretos de atingir os mesmos fatos empíricos." (SEARLE 1997, p. 73 [109])

21 A partir do momento em que podemos conhecer os fenômenos ontologicamente subjetivos, estamos autorizados a tomá-los como fenômenos reais.

22 A questão sobre se o privilégio da teoria do conhecimento na Filosofia desde o século XVII de fato levou à nega- 
ção da subjetividade ontológica (como afirma Searle) é uma questão relativa à História da Filosofia, um domínio que não me proponho a tratar no presente trabalho.

23 Ou seja, mesmo se estivéssemos autorizados a atribuir um certo estado mental a um outro ser - já que poderíamos constatar o processo cerebral subjacente a esse estado embora não pudéssemos vivenciar nós mesmos esse estado mental.

24 Reforçando as fileiras dos que interpretam o Naturalismo Biológico como uma forma de dualismo, Kemmerling escreve: "só o termo 'modo de existência' já deveria despertar suspeitas; ele lembra também o dualismo de Descartes, no qual são atribuídos dois 'modi essendi' a todas as coisas das quais a mente tem consciência." (KEMMERLING 1994, p. 438)

25 A consideração dessa problemática na filosofia da mente de Searle me evoca imediatamente a lembrança do célebre ensaio de Thomas Nagel, What is it like to be a bat?, onde o autor procura argumentar em favor da tese de que "nós não temos no presente nenhuma concepção do que seria uma explicação da natureza física de um fenômeno mental." (NAGEL 1974, p. 436) Destacando o caráter subjetivo da experiência consciente, caráter que me parece ser completamente aceito por Searle (cf. SEARLE 2002a, p. 39-40), Nagel afirma: "se os fatos da experiência - fatos a respeito de como é para o organismo que tem a experiência - são acessíveis apenas de um ponto de vista, então, é um mistério como o verdadeiro caráter [grifo meu] das experiências poderia ser revelado através das operações físicas do organismo." (NAGEL 1974, p. 442) Ao referir-me a Nagel no presente contexto, não pretendo endossar suas concepções acerca da subjetividade. Pretendo apenas destacar o fato de que, ao defender a te- 
se de um modo de existência subjetivo dos fenômenos mentais, Searle coloca a sua filosofia da mente diante da dificuldade apontada por Nagel para os projetos reducionistas. Searle parece querer, simultaneamente, defender um projeto, em certo sentido, reducionista, e conceber a subjetividade da maneira que faz Nagel, e é muito difícil entender como ele poderia, coerentemente, fazer essas duas coisas.

26 "Sustento uma visão de relações mente/cérebro que é uma forma de redução causal, conforme defini a noção: características mentais são causadas por processos neurobiológicos." (SEARLE 1997, p. 115 [166])

27 Partindo do ponto de vista dos defensores da tese de uma lacuna explanatória (explanatory gap) entre os processos cerebrais e o caráter qualitativo da experiência consciente, Martine Nida-Rümelin sintetiza a problemática da seguinte maneira: "Como tem sido claramente apontado por Levine, Chalmers e outros, o ponto não é que não possamos ter conhecimento sobre leis naturais que conectem estados do cérebro em termos de sua microestrutura com instanciações de propriedades-c. Se soubéssemos com base nos dados experimentais quais são exatamente as condições neurobiológicas para levar com necessidade nomológica a, por exemplo, a experiência de alegria, então em algum sentido poderíamos explicar com base em dados sobre o cérebro de uma dada pessoa por que ele ou ela experimenta alegria em um determinado momento. (...) Mas a possibilidade desse tipo de explicação nunca foi posta em dúvida por aqueles que defendem a tese da lacuna explanatória. Podemos, é claro, saber da conexão nomológica entre estados cerebrais e a experiência de alegria e ainda não ter entendimento de como acontece que um cérebro com uma certa microestrutura 
(a) leva à existência de um sujeito de experiência e (b) causa a ocorrência do tipo qualitativo específico em questão.” (NIDA-RÜMELIN 2002, p. 216). Na terminologia da autora "propriedades-c" são propriedades, "que um sujeito não pode ter (...) sem ter algum tipo de experiência." (Ibid, p. 206)

28 Cf. Hodgson (1994, p. 265): "A tentativa de Searle de evitar o dualismo, dizendo que o mental é físico, falha porque ele afirma fortemente o que equivale a um dualismo do objetivo e do subjetivo (cf. NAGEL 1993, p.40). Searle escolhe uma propriedade da consciência, que é a subjetividade, que a distingue totalmente de todas as outras propriedades de nível superior ou emergentes com as quais ele quer comparar - tais como as características biológicas como a digestão, ou características nãobiológicas como solidez e liquidez. A distinção que ele aponta entre o objetivo e o subjetivo merece o rótulo 'dualismo', porque ele afirma ambos, que as duas categorias são exaustivas de realidade empírica (certamente, ele não afirma nenhuma outra categoria) e também que elas são mutuamente irredutíveis (p. 98). Desse modo, o dualismo que ele afirma do objetivo e do subjetivo não é significativamente diferente do que ele nega, que é o do físico e mental." Em sua resenha de A Redescoberta da Mente, mencionada por Hodgson, Nagel afirma: "Dizer, além disso, que somos 'deixados com um universo que contém um componente físico subjetivo irredutível como um componente de realidade física' meramente arranja uma asserção essencialmente dualística na linguagem que expressa uma forte aversão ao dualismo." (NAGEL 1993, p. 40)

29 "não há como estudar os fenômenos da mente sem, implícita ou explicitamente, estudar a consciência. A razão 
básica disso é que realmente não temos noção do mental independentemente de nossa noção de consciência." (SEARLE 1997, p. 18 [31])

30 "A consciência tem três aspectos que a faz diferente de outros fenômenos biológicos e, na verdade, diferente de outros fenômenos no mundo natural." (SEARLE 2002a, p. 39) [grifo meu] Cf. Searle (1997: 93 [138]): "Os estados e processos mentais conscientes têm uma característica especial, não encontrada em outros fenômenos naturais, a saber, a subjetividade."

31 Gostaria de agradecer aos professores Andreas Kemmerling (Universidade de Heidelberg) e Guido Imaguire (UFC) pelos valiosos comentários a versões anteriores deste trabalho. Gostaria de agradecer também a Ananda Badaró de Athayde Prata pela revisão do texto.

\section{REFERÊNCIAS}

CHURCHLAND, Paul. Betty Crocker's Theory [Resenha de The Rediscovery of The Mind]. In: London Review of Book, v. XVI, no 9 (12), p. 13-4, May, 1994.

HODGSON, D. Why Searle Has Not Rediscovered The Mind. Journal of Consciousness Studies, v. 1, no 2, p. 264-74, Winter, 1994.

KEMMERLING, A. Von der Sprache zum Bewusstsein: John R. Searle löst sich vom analytischen Mainstream. Merkur deutsche Zeitschrift für europäisches Denken, v. 48, no 5, p. 432 8, 1994.

KIM, J. Mental Causation in Searle's 'Biological Naturalism'. Philosophy and phenomenological Research, v. 55(1), p. 189-94, 1995. 
LEVINE, J. On Leaving Out What Is Like. In: BLOCK/FLANAGAN/GÜZELDERE. The Nature of Consciousness: Philosophical Debates. Cambridge (Mass.): MIT Press, 1997, p. 543-555.

NAGEL, T. What Is It Like To Be a Bat? Philosophical Review, v. 83, p. 435-50, 1974.

The Mind Wins! [Resenha de The Rediscovery of The Mind] New York Review of Books, v. 4, p. 37-41, March, 1993.

NIDA-RÜMELIN, M. Causal Reduction, Ontological Reduction and First-Person Ontology. Notes on Searle's Views about Conciousness. In GREWENDORF, G.; MEGGLE, G. (Org.) Speech Acts, Mind and Social Reality: Discussions with John R. Searle. Dordrecht, Boston, London: Kluwer Academic Publishers, 2002, pp. 205-21.

SEARLE, J. R. Mente, Cérebro e Ciência. Lisboa: Edições 70, 1987. [original: Minds, Brains and Science. Cambridge Mass., Harvard University Press. (1984)]

. Searle, John. In: GUTTENPLAN, S. (Ed.) A Companion To The Philosophy of Mind. Oxford/Cambridge MA: Basil Blackwell, 1994.

. The Construction of Social Reality. New York: The Free Press, 1995.

- A Redescoberta da Mente. São Paulo: Martins Fontes, 1997. [original: The Rediscovery of the Mind. Cambridge Mass., London: MIT Press. (1992)]

- Mente, Linguagem e Sociedade: filosofia no mundo real. Rio de Janeiro: Ed. Rocco, 2000. [original: Mind, Language 
and Society: Philosophy in the Real World. New York: Basic Books, (1998)]

. Meaning, Mind and Reality. Revue Internationale de Philosophie, no 217, p. 173-9, 2001.

. Consciousness and Language. Cambridge (UK): Cambridge University Press, 2002a.

. Why I Am Not a Property Dualist. Journal of Consciousness Studies, v. 9, no 12, p. 57-64, 2002b.

. Mind: a brief introduction. Oxford: Oxford University Press, 2004.

STICH, S.P. [Resenha de Minds, Brains and Science]. The Philosophical Review, v. 96, p. 129-33, 1987.

THOMPSON, D.L. Intentionality and causality in John Searle. Canadian Journal of Philosophy, v. 16, p. 83-97, 1986. 